prefer treating smaller babies in the constant negative pressure respirator.-I am, etc.,

Department of Paediatrics,

University of Stellenbosch,

Tiervlei, C.P.

South Africa

Gregory, G. A., et al., New England Fournal of Our Lady's Hospice, of the morning. Possibly being at a low ebb ourselves when called from a warm bed we feel that the patient should be at the point of deaih.-I am, etc.,

JOHN FLEETWOOD

Medicine, 1971, 284, 1333 .

\section{Solids and "Sleeping through"}

SIR,-A survey into infant feeding habits has been carried out in South-east Monmouthshire on 100 mothers with babies between 6 weeks and 6 months of age. The major purpose of the survey was to ascertain whether there was a demonstrable link, as popularly believed, between introducing solids into the diet and giving up the 2 a.m. night feed. Only eight of the 100 mothers had not yet started solids (cereal in all but two cases) and all these had babies between 6 and 12 weeks old.

Of the 91 babies in whom the age of dropping the night feed was known, 49 had done so before, 18 during, and 14 after the introduction of cereal. Thus in only 32 cases could one even postulate a relationship between the introduction of cereal and sleeping through the night, and in 14 of these there was a delay of two or more weeks.

We are therefore unable to sustain the belief of many mothers (and others) that cereal feeding leads to babies sleeping through the night. If there were such a relationship it would be difficult to blame a mother who tried to ensure a good night's sleep for herself and the rest of the family. Perhaps these findings may help to counter some rather persuasive advertising and to avoid sowing some of the seeds of infant obesity.-I am, etc.

Newport, Mon

\section{R. M. ROBERTSON}

\section{Time of Death}

SIR,-In the course of a recent Horizon broadcast the statement was made that most deaths occur about three o'clock in the morning, and this is a widespread belief both in the profession and elsewhere. Among the distinguished authors who have perpetuated the myth was Robert Louis Stevenson.

Over the past two years I have kept a note of the time of death of every patient in this long-term and terminal care unit and, as the chart shows, these were distributed fairly

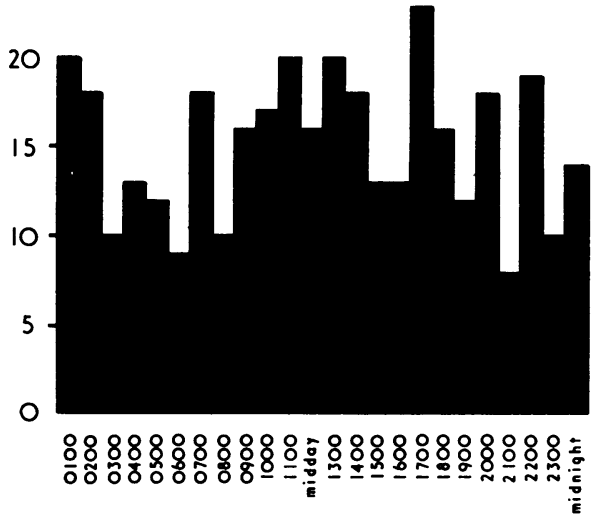

Distribution of times of death (corrected to nearest hour) of 363 patients.

\section{Intermittent Claudication and Vitamin E Therapy}

SIR,-I was most interested in the finding by Mr. J. A. Dormandy and others ( 8 December, p. 576) of raised red cell malonyldiaydehyde content in patients with intermittent claudication. I understand that this reflects the susceptibility of red cell lipids to auto-oxidation, malonyldialdehyde being a secondary breakdown product of lipid peroxides. Lipid peroxide is known to damage cell membranes and is known to be present in human atheromatous lesions. ${ }^{1}$ Perhaps, as Mr. Dormandy and his colleagues suggest, the breakdown products of autooxidation have an effect on blood vessels and in pain causation.

In an excellent survey of the therapeutic value of vitamin $\mathrm{E}$ Marks² reviews the evidence for its use in intermittent claudication and concludes that there is a very sound basis for its use on grounds of clinical improvement. Vitamin $\mathrm{E}$ is known to inhibit lipid peroxidation in vitro ${ }^{3}$ and is a known in vivo lipid antioxidant. These facts and the authors' findings in patients with intermittent claudication might add more weight and some theoretical basis for vitamin $E$ therapy in this potentially crippling yet often unrelievable condition.-I am, etc.,

William D. Alexander

Bristol Royal Infirmary,

Bristo Glavind, J., Hartmann, S., Clemmesen, J., Jessen,
K. E., and Dam, H., Acta Pathologica et Microbiologica Scandinavica, 1952, 30 .

Tappel, A. L., Archives of Biochemistry and
Biophysics, 1959, 80, 333.

3 Marks, J., Vitamins and Hormones, 1962, 20, 573.

\section{Doctors in South Africa}

SIR,- - In your leading article on the World you state that "too little credit is sometimes given to the Medical Association of South Africa for what it does under difficult circumstances." This opinion is most unlikely to be shared by any of the Black doctors in South Africa. On numerous occasions Black doctors in Cape Province, Natal, and Transval have separately urged the M.A.S.A. to take up their grievances with the authorities. It is interesting to note that the Federal Council of the M.A.S.A. has never included an elected representative of Black doctors whenever they have met the authorities to discuss their grievances. Blacks in South Africa are naturally very suspicious when matters of vital importance to them are discussed by Whites in their absence.

Despite the fact that all English-speaking newspapers in South Africa now use "African" when referring to the indigenous population, the South African Medical fournal continues using "Bantu" irrespective of the wish of the authors. The Nationalist Government never uses the word "African" as Medical Association (3 November, p. 245) this would in a way acknowledge that they were the earliest inhabi.ants of South Africa. This is contrary to their version of South African history. The editor of the S.A.M.F. also does not allow the use of "Black" instead of "non-White." However, "Whites" have never been referred to as "non-Blacks" in the journal. We should all strive for the day when people are no longer referred by their colour. Anyway, Blacks and Whites are incorrect terms; we are all varying shades of brown, pink, and yellow.-I am, etc.,

F. DINDAR

Etobicoke, Qntario

\section{Testing Factory Workers for Glycosuria}

SIR,-Clinistix strips were placed, with suitable instructions, in the pay envelopes of 13,466 employees working in an aero engine factory in Bristol. This exercise was publicized on the works notice boards after the permission of the management and the cooperation of the unions had been obtained. Known cases of diabetes were excluded. A total of 7,169 strips were returned. When the result was positive the urine was retested, and in 67 cases was found to contain sugar in amounts varying from $\frac{1}{4} \%$ to $2 \%$. All employees with more than $1 \%$ of sugar in their urine were referred to their own doctors for further investigation. In 38 of these cases the diagnosis of diabetes was confirmed after a glucose tolerance test. Of these 38 diabetics, 21 are now controlled by diet only and the rest, showing smaller amounts of sugar in the urine, are also sugar-free with carbohydrate restriction.

This exercise, the cost of which amounted to $£ 147$, was thought to be a useful preventive measure in a large works. We have now passed on to phase 2 of our preventive measures and are testing the blood pressure of all employees over the age of $40 .-\mathrm{I}$ am, etc.,

E. P. GRIfFiths Senior Medical Officer, Bristol Engine Division

Bristol

SIR,-I was interested to read your leading article "Glucagon Therapy in Acute Pancreatitis" (1 December, p. 503). Unfortunately, the trial of glucagon reported by Condon et al.,1 to which you refer, has done little to establish the drug's usefulness since they had no controls and, like vour article, used the figures of Efron ${ }^{2}$ and of Trapnell ${ }^{3}$ who reported mortalities of $22 \%$ and $23 \%$ respectively. Of Trapnell's series only $63 \%$ were diagnosed clinically and only 95 of his 324 patients underwent laparotomy. Efron does not give his laparotomy figures. Trapnell considered diagnostic laparotomy to be a fairly safe procedure, a point which may be debatable, but interestingly enough 13 patients out of Condon's series of 30 underwent laparotomy. Corlett and Mishell, ${ }^{4}$ studying the disease in pregnancy, (admittedly a selected group) had no mortality. Unpublished figures for this area on a series of 45 patients give a mortality of $8.8 \%$ or, excluding postoperative deaths, $4 \cdot 7 \%$. My point is that statistics of mortality from acute 